\title{
Needs driven talent and competency development for the next generation of regulatory scientists in Africa
}

\author{
Boitumelo Semete-Makokotlela ${ }^{1}$, Gugu Mahlangu², David Mukanga ${ }^{3}$, Delese Darko ${ }^{4}$, Peter \\ Stonier $^{5}$, Luther Gwaza ${ }^{6}$, Portia Nkambule ${ }^{1}$, Precious Matsoso ${ }^{7}$, Regine Lehnert ${ }^{8}$, B \\ Rosenkranz $^{9}$, and Goonaseelan Pillai ${ }^{10}$ \\ ${ }^{1}$ South African Health Products Regulatory Authority \\ ${ }^{2}$ Medicines Control Authority of Zimbabwe \\ ${ }^{3}$ Bill \& Melinda Gates Foundation \\ ${ }^{4}$ Food and Drug Authority Ghana \\ ${ }^{5}$ King's College London Faculty of Life Sciences and Medicine \\ ${ }^{6}$ World Health Organization \\ ${ }^{7}$ Health Regulatory Science Platform \\ ${ }^{8}$ Federal Institute for Drugs and Medical Devices \\ ${ }^{9}$ Stellenbosch University Department of Medicine \\ ${ }^{10} \mathrm{CP}$ Plus Associates
}

February 25, 2021

\begin{abstract}
There is a critical skills gap on the African continent in regulatory sciences, and an acknowledged need to develop a long-term strategy for training and professional development of African regulatory personnel. Capacity building programs for African regulators should link education, training and research with career development in an approach that combines an academic base and experiential learning aligned within a competency framework. A regulatory ecosystem that engages with a broad range of stakeholders will mean that expertise in the ever-expanding field of regulatory science filters into teaching and research in a symbiotic way. In this way capacity development interventions will be a collaborative approach between the learning context (academic and training institutions) and the performance context (regulatory agencies and industry), which will ultimately best serve the patients. Monitoring and evaluation of capacity development interventions will be essential to show value of investments and ultimately guide continued funding and sustainability. This paper reviews the skills and human capacity gap and outlines a staged tactical approach for Africa that builds on previous efforts to strengthen African regulatory ecosystems.
\end{abstract}

\section{Hosted file}

Competency_development_for_regulatory_scientists_in_Africa_23Feb2021.pdf available at https://authorea.com/users/398232/articles/510876-needs-driven-talent-and-competencydevelopment-for-the-next-generation-of-regulatory-scientists-in-africa

\section{Hosted file}

Competency_development _for_regulatory_scientists_in_Africa_Table 1.pdf available at https://authorea.com/users/398232/articles/510876-needs-driven-talent-and-competencydevelopment-for-the-next-generation-of-regulatory-scientists-in-africa 